\title{
Differences in particle characteristics and oxidized flavor as affected by heat-related processes of milk powder
}

\author{
Y. H. Li, L. W. Zhang, ${ }^{1}$ W. J. Wang, and X. Han \\ School of Food Science and Engineering, Harbin Institute of Technology, Harbin 150090, PR China
}

\begin{abstract}
Understanding the formation of oxidized flavor will be highly useful in the improvement of milk powder quality. Effects of preheating, concentration and spraydrying on the particle characteristics and the oxidized flavor stability of milk powder were investigated. The surface composition and free radicals were analyzed using x-ray photoelectron spectroscopy and electron spin resonance spectrometry, respectively. The concentrations of selected oxidized volatiles hexanal and 2-heptanone were determined using solid-phase microextraction gas chromatography-mass spectrometry. Levels of hexanal and 2-heptanone in fresh milk powder were higher than those in raw milk and heated milk, which drastically increased with increasing time of storage. Differences in the morphological observations, free fat, and surface composition of fresh milk powder were found among different heat-related processes. During storage, a radical ( $\mathrm{g}$ value, a characteristic constant whose value serves to identify any given free radical, was 2.0054) was detected in milk powder. The specific population of the radical increased from $2.99 \times 10^{7}$ at 3 mo to $1.23 \times 10^{8}$ at 6 mo of storage. Addition of ascorbic acid in milk powder changed the type of radicals and reduced the oxidation off-flavor. According to the Pearson correlations, not the surface compositions but the morphological characteristics of milk powder particles should be considered in maintaining the stability of oxidized flavor in storage.
\end{abstract}

Key words: oxidized flavor, particle characteristics, milk powder, process

\section{INTRODUCTION}

The flavor quality of milk powder is highly associated with consumer acceptability. Milk powder is very susceptible to oxidation, resulting in oxidation off-flavor. Oxidized flavor is the total description of metallic, soapy, papery, fatty, mushroom, and fishy flavor in dairy

Received June 3, 2012.

Accepted April 23, 2013.

${ }^{1}$ Corresponding author: lanweizhang@yahoo.com.cn products (Timmons et al., 2001; Hedegaard et al., 2006; Lloyd et al., 2009a). Oxidized flavor is the most critical factor in restricting flavor characteristics and shelf life of milk powder (Whetstine and Drake, 2007; Lloyd et al., 2009a). The milk powder industry is confronted by situations where powders demonstrate lower flavor stability than expected. Increasing the storage stability of this commodity is of great interest to producers and end users (Nielsen et al., 1997; Lloyd et al., 2009b).

Certain compounds contribute to the oxidized flavor, such as aldehydes, ketones, and lactones, which have been indicated to be formed via lipid oxidation (Nielsen et al., 1997; Cadwallader and Singh, 2009). Some factors that influence the oxidized volatiles and their stability in storage of milk powder have been conducted, including initial milk quality, processing variables, moisture content, packaging, oxygen exposure, light exposure, and storage temperature (Baldwin et al., 1991; Stapelfeldt et al., 1997; Whetstine and Drake, 2007; Lloyd et al., 2009b). However, these studies were focused on the preheating treatments of milk and the storage of milk powder. The effect of heat-related processing variables on the formation of oxidized flavor in milk powder was limited.

The fat fraction of milk powder is the most important for the development of oxidized flavor. Free radicals, peroxide value, and thiobarbituric acid-reactive substances have been used as indicators for evaluation of the lipid oxidation of dairy products (Stapelfeldt et al., 1997; Kristensen et al., 2002; Thomsen et al., 2005). Few recent studies on free fat and surface fat of powder particles (Kim et al., 2002, 2003, 2005, 2009a; Vignolles et al., 2010) reported that drying could affect the formation and presence of free fat at the surface of powder particles. Additional detailed studies are needed to understand the formation of oxidized flavor and milk powder particles as affected by different processes. The aims of the study were to (1) determine the changes in oxidized flavor of milk powder as affected by different processes, (2) investigate the difference in particle characteristics of milk powder due to different processes, and (3) evaluate the free radical in storage and the effect of antioxidants on oxidized flavor of milk powder. 


\section{MATERIALS AND METHODS}

\section{Manufacture of Milk Powder}

Raw milk (RM) obtained from a local dairy plant had $0.02 \%$ (wt/vol) $\mathrm{NaN}_{3}$ added to it to prevent bacterial growth and was stored at 4 to $6^{\circ} \mathrm{C}$. Heated milk (HM) was prepared according to the method of Lee and Sherbon (2002), with the intensity of $90^{\circ} \mathrm{C}$ for 30 s. The milk was cooled to ambient temperature $(20 \pm$ $1^{\circ} \mathrm{C}$ ) in a stirred water bath at 0 to $4^{\circ} \mathrm{C}$ and prepared for concentration and drying. The RM (and HM) was concentrated to 4 times at $40^{\circ} \mathrm{C}$ and 3 times at $50^{\circ} \mathrm{C}$ under 0.1 MPa pressure. The concentrated milks were subclassified according to the temperature of concentration. Spray-drying for RM, HM, and the concentrated milk of RM and HM (RMC and HMC, respectively) was done using a laboratory-scale spray dryer (EYELA SD-1000; Tokyo Rikakikai Co. Ltd., Tokyo, Japan). The milk powder of RM, HM, RMC, and HMC (RMP, HMP, RMCP, and HMCP, respectively) was subclassified according to the inlet-air temperature (160 and $190^{\circ} \mathrm{C}$ ). Other parameters were as follows: nozzle pressure $=20 \mathrm{MPa}$, feed flow rate $=400$ to $600 \mathrm{~mL} / \mathrm{h}$, and flow rate of drying air $=40$ to $60 \mathrm{~m}^{3} / \mathrm{h}$. The outletair temperature was controlled at $85^{\circ} \mathrm{C}$ by adjusting the speed of material and hot air. Milk powder was stored in a dry and air-tight container at ambient temperature for 3 and 6 mo for flavor analysis.

\section{Component Analyses of Milk}

Fat content was determined by the Röse-Gottlieb method and total protein by the Kjeldahl technique with a factor of 6.38 , as described by Guinee et al. (2000). The free fat was extracted using the method described by Kim et al. (2005). The extracted fat value was then recorded as grams of free fat per gram of fresh powder. The concentrated milk and milk powder were reconstituted for analysis according to the TS by adding back with Milli-Q water (Millipore Corp., Billerica, MA). Total solids content of milk and moisture content (\%) of milk powder were calculated according to the weight loss by drying the samples at $105 \pm 1^{\circ} \mathrm{C}$ (Almeida et al., 2009; Kim et al., 2009a).

\section{Morphological Observation of Particles}

Milk powder $(0.1 \mathrm{~g})$ was dissolved in $10 \mathrm{~mL}$ of acetone. After homogeneously mixing, a drop was placed into a blood cell count plate and observed under an optical microscope (CX31; Olympus Corp., Tokyo, Japan). Five horizons were selected randomly from the digital camera imaging of milk powder particles.
Particle size and morphological image were analyzed using Image-Pro Plus (IPP) software (Image-Pro Plus 6.0; Media Cybernetics Inc., Rockville, MD).

\section{Surface Composition of Powder Particles}

The elemental surface composition of different powders was determined using an X-ray photoelectron spectroscopy (XPS) system (K-Alpha; Thermo Fisher Scientific Co., Waltham, MA) according to the method of Kim et al. (2009a). The scan interval of the monochromator for full spectrum was $1.0 \mathrm{eV}$. The elements $\mathrm{C}, \mathrm{O}, \mathrm{N}, \mathrm{P}$, and $\mathrm{S}$ were scanned and the step size was $0.1 \mathrm{eV}$.

\section{Determination of Volatiles}

The volatiles in the headspace of the samples (RM, HM, concentrated milk, and reconstituted milk powder) were extracted and analyzed using solid-phase microextraction gas chromatography-mass spectrometry (SPME-GC-MS) according to a previous study (Li et al., 2012). Hexanal and 2-heptanone, as selected oxidized volatiles, were identified by the National Institute of Standards and Technology (Gaithersburg, MD) NIST-02L GC-MS spectrum library and the retention time of their standard chemicals (Sigma, St. Louis, $\mathrm{MO})$.

\section{Detection of Free Radicals in Milk Powder}

The radicals were measured by an electron spin resonance (ESR) spectrometer (model A200S-95/12; Bruker BioSpin GmbH, Rheinstetten, Germany). Electron spin resonance analysis was based on the method described by Thomsen et al. (2005). Different instrument parameters used were as follows: sweep width $=$ 100 Gauss (0.01 Tesla), microwave power $=3.10 \mathrm{~mW}$, modulation amplitude $=1.00$ Gauss $\left(1.0 \times 10^{-4}\right.$ Tesla $)$, receiver gain $=5.02 \times 10^{4}$, time constant $=40.96 \mathrm{~ms}$, conversion time $=160 \mathrm{~ms}$, and total sweep time $=$ $163.84 \mathrm{~s}$.

\section{Effect of Antioxidants on Oxidized Volatiles}

The parameters of $\mathrm{HMC}_{50} \mathrm{P}_{190}$ (the subscript numbers indicate that concentration was performed at $50^{\circ} \mathrm{C}$ and drying was performed at $190^{\circ} \mathrm{C}$ ) were used in the production of milk powder for the experiment of antioxidants addition. Chemical-grade $\alpha$-tocopherol (TOC) and L-ascorbic acid (ASC) were obtained (Sigma). Before drying, $0.05 \%$ (wt/vol) TOC, $0.05 \%$ (wt/vol) ASC, and $0.025 \%(\mathrm{wt} / \mathrm{vol}) \mathrm{TOC}$ and ASC were added into the concentrated milk. The milk powder products were 
stored at $30^{\circ} \mathrm{C}$ for $2 \mathrm{wk}$ aerobically, exposed to light or protected against light. The SPME-GC-MS and ESR were carried out for analyzing oxidized volatiles and free radicals in milk powder.

\section{Statistical Analysis}

Analyses were duplicated for the SPME-GC-MS and expressed as means, and triplicated and expressed as mean \pm standard deviation for others. One-way and univariate ANOVA for determining the effect of the processes were carried out using PASWStatistics18.0 software (SPSS Inc., Chicago, IL). Pearson correlation (2-tailed) was used for analyzing the relationship between the oxidized volatiles and particle characteristics.

\section{RESULTS AND DISCUSSION}

\section{Milk Components Analysis}

The raw milk from the same plant was used to produce the milk powder with 2-d intervals. No significant difference was observed in the main composition among different batches $(P>0.05)$. The average contents of the components in raw milk were as follows: $\mathrm{TS}=11.72$ $\pm 0.35 \%$, protein $=3.08 \pm 0.15 \%$, and fat $=2.97 \pm$ $0.12 \%$. The composition parameters of all milk powders were as follows: protein $=26.5 \pm 2.3 \%$, fat $=25.7 \pm$ $3.7 \%$, and humidity $=3.5 \pm 0.3 \%$. No difference was observed among the samples manufactured by different processes $(P>0.05)$. Their contents were within the ranges of international standards (Lloyd et al., 2009a).

\section{Particle Sizes of Milk Powders}

The underlying principle of IPP software and its application to image analysis have been described elsewhere (Bullman, 2003). Figure 1A was the original image of milk powder particles. Using the IPP software, the powder particles could be differentiated from impurities by the difference in diameter $(>10 \mu \mathrm{m})$ and divided into 2 groups according to the radius ratio. The results are shown in Figure $1 \mathrm{~B}$ (radius ratio $=1-2.5$ ) and Figure 1C (radius ratio $>2.5$ ). Based on that, the quantitative information of the 2 groups was acquired as shown in Figure 1D. The particle diameters of milk powder were mainly concentrated around $30 \mu \mathrm{m}$ and the radius ratio ranged from 1 to 2.5 .

Differences in particle diameters could be found among milk powder produced by different processes. As shown in Table 1, the unconcentrated milk powder (RMP and HMP) had smaller particle size than their corresponding concentrated milk powders (RMCP and HMCP; $P<0.05)$. Especially, milk powder when concentrated at $40^{\circ} \mathrm{C}$ had larger sizes than when concentrated at $50^{\circ} \mathrm{C}(P<0.05)$. According to the results of univariate ANOVA (particle sizes by preheating, concentration, and spray-drying), we found that the concentration and drying influenced particle sizes $(P=$ 0.000 and 0.025 , respectively), whereas heating had no influence $(P=0.19)$.

Spray-drying is an important process for the production of milk powder. In the first stage of drying, the free water in milk droplets transfers to the surface and then the hard shell is formed. In the second stage, the internal collapse of the particles occurs, and finally forms a solid shape (Hassan and Mumford, 1993). The results of univariate ANOVA suggest that the feed concentration and drying temperature influenced the transfer speed of water and the forming speed of the shell and, consequently, influenced the distributions of particles sizes.

\section{Free Fat of Milk Powder}

Table 1 shows the contents of free fat in different milk powders. The range of free fat was 4.57 to $8.24 \mathrm{~g}$ of fat $/ \mathrm{kg}$ of fresh powder. The differences among the powder samples are quite occasional and not regular, which might be due to the extracted fat remaining behind on the filter paper and the glassware (Kim et al., 2005). However, the results of univariate ANOVA (surface free fat by heating, concentration, and drying processes) showed that the drying influenced surface free fat $(P=0.001)$, whereas the single process of heating $(P=0.46)$ or concentration $(P=0.64)$ had no significant influence.

Free fat can originate from physical damage due to shrinkage at the early stages of spray-drying (Vignolles et al., 2007, 2010). In the research, the free fat was extracted using solvent within a prefixed time and, thus, originated not only from the surface but also from the pores of the powder particles. According to the results of mean values and univariate ANOVA, the spray-drying conditions influenced the release of free fat due to the damage during shrinkage of droplets while drying. This released fat is readily susceptible to oxidation and formation of oxidized flavor of milk powder.

\section{Surface Compositions of Milk Powders}

The typical XPS spectra of milk powder particles are graphically presented in Figure 2. In the spectra, the peaks of elemental $\mathrm{C}$ and $\mathrm{O}$ were found clearly. In the narrow scan of elemental $\mathrm{C}$ (Figure 2B), the binding energy of approximately $284 \mathrm{eV}$ represented C-C, C-H, and $\mathrm{C}-\mathrm{O}-\mathrm{H}$ bonds, whereas the energy of approximately $289 \mathrm{eV}$ represented mainly $\mathrm{C}=\mathrm{O}$ bonds. Elemental 
Table 1. Processing parameters, particle size, and free-fat content of milk powder

\begin{tabular}{|c|c|c|c|c|c|}
\hline $\begin{array}{l}\text { Milk } \\
\text { powder }^{1}\end{array}$ & Heating & Concentration & $\begin{array}{c}\text { Drying } \\
\text { temperature }\left({ }^{\circ} \mathrm{C}\right)\end{array}$ & $\begin{array}{l}\text { Particle } \\
\text { size }(\mu \mathrm{m})\end{array}$ & $\begin{array}{c}\text { Free fat } \\
(\mathrm{g} / \mathrm{kg} \text { of milk powder) }\end{array}$ \\
\hline $\mathrm{RMP}_{160}$ & Unheated & Unconcentrated & 160 & $34.04 \pm 1.84^{\mathrm{a}}$ & $6.83 \pm 0.47^{\mathrm{abc}}$ \\
\hline $\mathrm{RMP}_{190}$ & Unheated & Unconcentrated & 190 & $35.60 \pm 1.21^{\mathrm{ab}}$ & $6.08 \pm 0.33^{\mathrm{abc}}$ \\
\hline $\mathrm{HMP}_{190}$ & $90^{\circ} \mathrm{C} / 30 \mathrm{~s}$ & Unconcentrated & 190 & $34.65 \pm 2.07^{\mathrm{a}}$ & $5.80 \pm 0.33^{\mathrm{abc}}$ \\
\hline $\mathrm{RMC}_{40} \mathrm{P}_{160}$ & Unheated & $40^{\circ} \mathrm{C}^{3}$ & 160 & $51.17 \pm 3.48^{\mathrm{d}}$ & $5.67 \pm 0.54^{\mathrm{abc}}$ \\
\hline $\mathrm{RMC}_{40} \mathrm{P}_{190}$ & Unheated & $40^{\circ} \mathrm{C}^{3}$ & 190 & $53.60 \pm 3.23^{\mathrm{d}}$ & $5.07 \pm 0.39^{\mathrm{a}}$ \\
\hline $\mathrm{RMC}_{50} \mathrm{P}_{190}$ & Unheated & $50^{\circ} \mathrm{C}^{4}$ & 190 & $43.78 \pm 3.30^{\mathrm{c}}$ & $6.42 \pm 0.81^{\mathrm{abc}}$ \\
\hline $\mathrm{HMC}_{50} \mathrm{P}_{160}$ & $90^{\circ} \mathrm{C} / 30 \mathrm{~s}$ & $50^{\circ} \mathrm{C}^{4}$ & 160 & $39.08 \pm 2.20^{\mathrm{abc}}$ & $5.46 \pm 0.81^{\mathrm{ab}}$ \\
\hline $\mathrm{HMC}_{50} \mathrm{P}_{190}$ & $90^{\circ} \mathrm{C} / 30 \mathrm{~s}$ & $50^{\circ} \mathrm{C}^{4}$ & 190 & $42.68 \pm 1.90^{\mathrm{bc}}$ & $4.57 \pm 0.72^{\mathrm{a}}$ \\
\hline
\end{tabular}

${ }^{\mathrm{a}-\mathrm{d}}$ Results within a column with the same superscript letters were not significantly different $(P>0.05)$.

${ }^{1} \mathrm{RMP}=$ milk powder of raw milk $(\mathrm{RM}) ; \mathrm{HMP}=$ milk powder of heated milk $(\mathrm{HM}) ; \mathrm{RMCP}=$ milk powder of concentrated $\mathrm{RM} ; \mathrm{HMCP}=$ milk powder of concentrated HM. The subscript numbers indicate that concentration was performed at 40 or $50^{\circ} \mathrm{C}$ and drying was performed at 160 or $190^{\circ} \mathrm{C}$

${ }^{2}$ The inlet temperature of heating air.

${ }^{3}$ Concentration was performed at $40^{\circ} \mathrm{C}$ to one-fourth of milk volume.

${ }^{4}$ Concentration was performed at $50^{\circ} \mathrm{C}$ to one-third of milk volume.

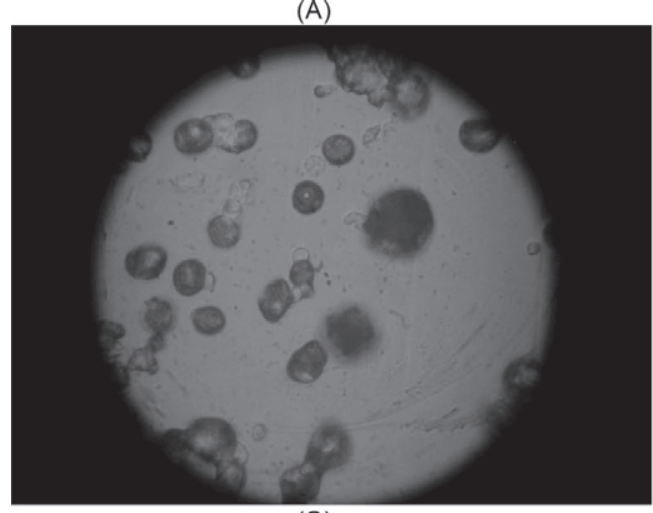

(C)

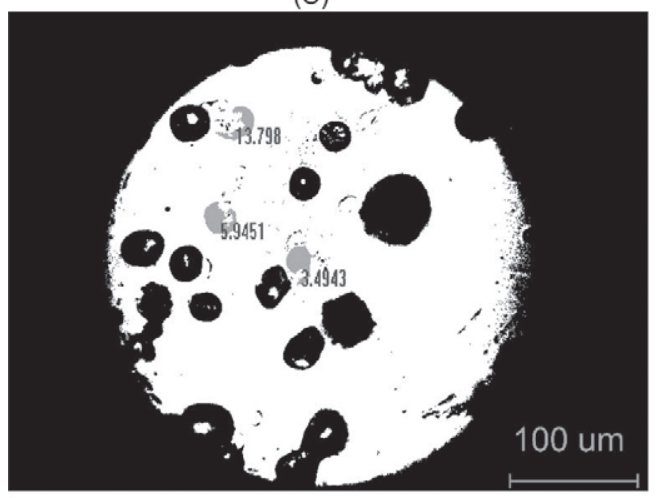

(B)

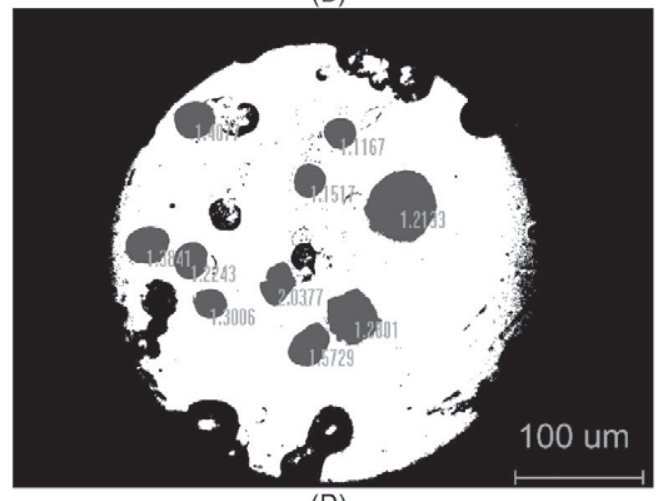

(D)

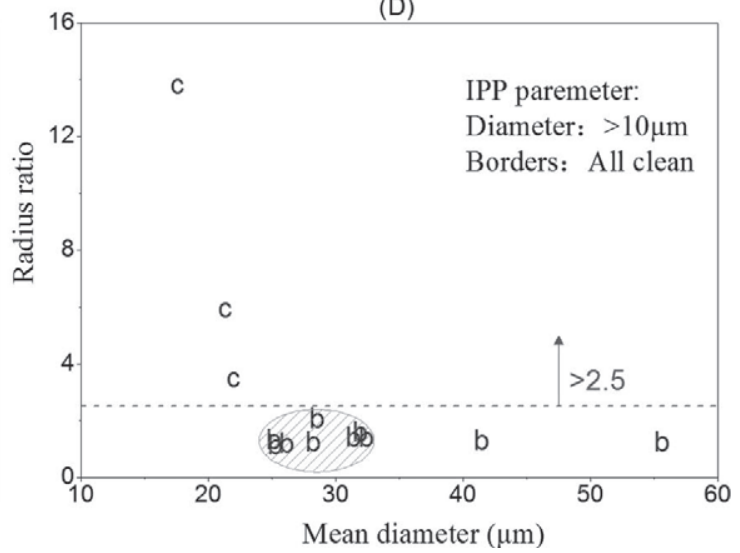

Figure 1. Image-Pro Plus (IPP; Image-Pro Plus 6.0; Media Cybernetics Inc., Rockville, MD) image analysis of milk powder particles. (A) The original image of milk powder particles; (B) the spherical particles (in gray) selected by radius ratio from 1 to 2.5 ; (C) the irregular particles (in gray) selected by radius ratio $>2.5$; (D) IPP information on the radius ratio and mean diameter of the selected particles. The lowercase letters ( $\mathrm{b}$ and $\mathrm{c}$ ) in panel D indicate that the radius ratio of milk powder particles was below 2.5 and above 2.5, respectively. Numbers labeled on particles are the values of the radius ratio. 

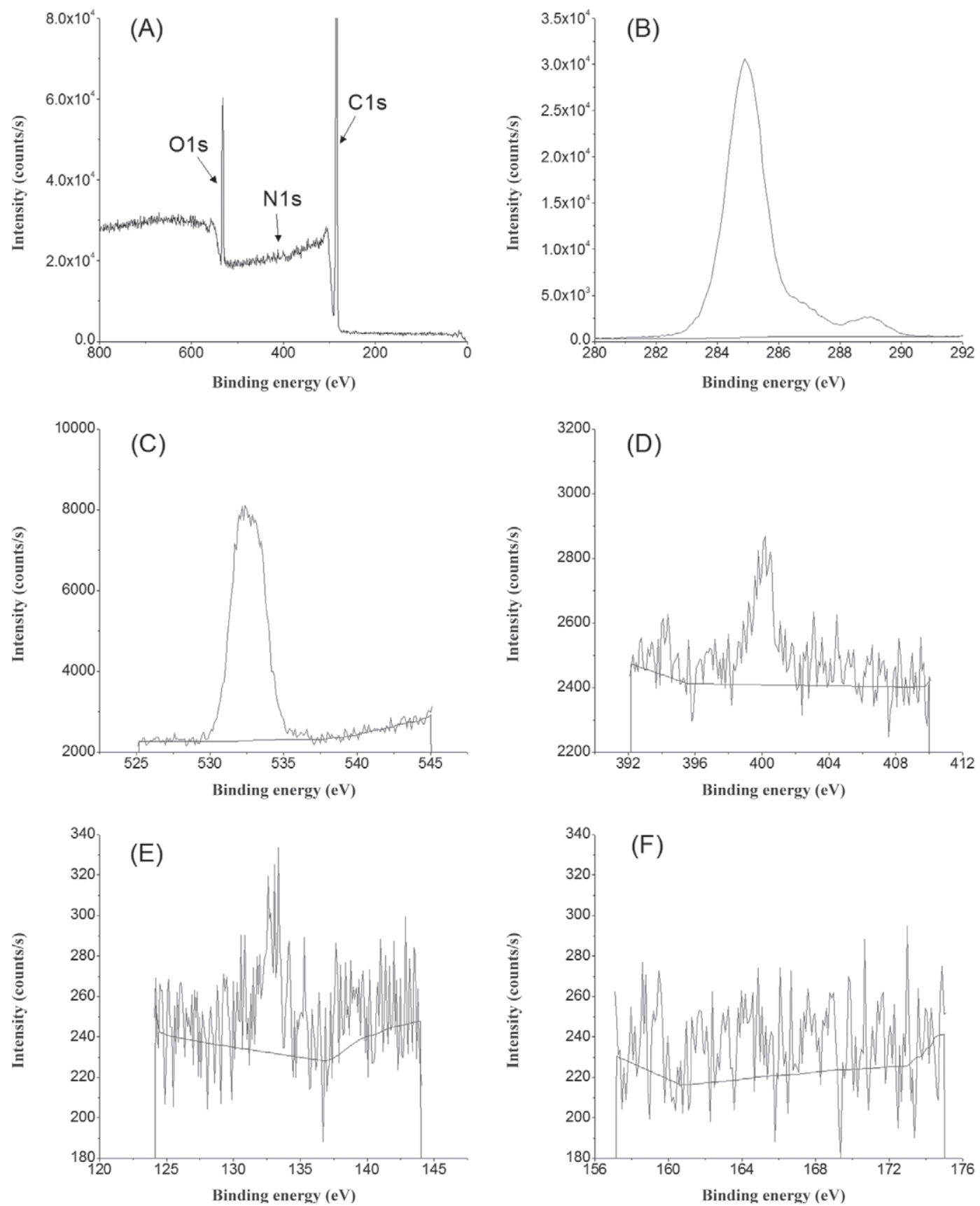

Figure 2. Typical X-ray photoelectron spectroscopy (XPS) spectra of milk powder: total scanning (A) at 1.0-eV intervals and narrow spectra of elemental carbon (B), oxygen (C), nitrogen (D), phosphorus (E), and sulfur (F) at 0.1-eV intervals.

$\mathrm{N}$ was detected in all the milk powder samples. But elemental $\mathrm{P}$ exists occasionally and irregularly, which might be related to its trace-level concentration. With the testing parameters, elemental S was not found.

Although milk powder contains many components, it was considered to be composed of only 3 main components (lactose, protein, and fat) for the XPS measurement (Kim et al., 2003). According to the relative atomic ratio of $\mathrm{C}, \mathrm{O}$, and $\mathrm{N}$, the contents of lactose, protein, and milk fat could be calculated. Table 2 shows the surface composition of different milk powders. The concentrations of protein (13.52-18.78\%) were lower in the surface than in the bulk composition of the milk powder. Meanwhile, the concentrations of fat (34.17-62.72\%) were higher than those in the bulk composition. The results were different from those of the previous study (Kim et al., 2002), in which it was reported that the surface of milk powder was covered 
Table 2. Distribution of surface composition in different milk powders

\begin{tabular}{lccc}
\hline & \multicolumn{3}{c}{ Composition $(\%)$} \\
\cline { 2 - 4 } Milk & Lactose & Protein & Fat \\
\hline powder $^{1}$ & $34.14 \pm 1.97^{\mathrm{ab}}$ & $14.82 \pm 0.11^{\mathrm{ab}}$ & $51.05 \pm 2.07^{\mathrm{cde}}$ \\
$\mathrm{RMP}_{160}$ & $40.10 \pm 2.10^{\mathrm{bc}}$ & $14.89 \pm 0.52^{\mathrm{abc}}$ & $45.02 \pm 1.58^{\mathrm{abc}}$ \\
$\mathrm{RMP}_{190}$ & $39.32 \pm 0.41^{\mathrm{bc}}$ & $17.53 \pm 1.05^{\mathrm{cd}}$ & $43.15 \pm 1.47^{\mathrm{abc}}$ \\
$\mathrm{HMP}_{190}$ & $47.06 \pm 2.93^{\mathrm{c}}$ & $18.78 \pm 0.59^{\mathrm{d}}$ & $34.17 \pm 3.51^{\mathrm{a}}$ \\
$\mathrm{RMC}_{40} \mathrm{P}_{160}$ & $23.77 \pm 5.01^{\mathrm{a}}$ & $13.52 \pm 0.58^{\mathrm{a}}$ & $62.72 \pm 5.59^{\mathrm{e}}$ \\
$\mathrm{RMC}_{40} \mathrm{P}_{190}$ & $36.13 \pm 0.09^{\mathrm{bc}}$ & $13.99 \pm 0.42^{\mathrm{ab}}$ & $49.89 \pm 0.33^{\mathrm{cd}}$ \\
$\mathrm{HMC}_{40} \mathrm{P}_{160}$ & $31.54 \pm 4.31^{\mathrm{ab}}$ & $14.13 \pm 0.71^{\mathrm{ab}}$ & $54.33 \pm 5.01^{\mathrm{cde}}$ \\
$\mathrm{HMC}_{40} \mathrm{P}_{190}$ & $40.76 \pm 2.69^{\mathrm{bc}}$ & $16.23 \pm 0.48^{\mathrm{bcd}}$ & $43.01 \pm 2.21^{\mathrm{abc}}$ \\
$\mathrm{RMC}_{50} \mathrm{P}_{160}$ & $24.42 \pm 4.12^{\mathrm{a}}$ & $14.15 \pm 0.63^{\mathrm{ab}}$ & $61.44 \pm 3.49^{\mathrm{de}}$ \\
$\mathrm{HMC}_{50} \mathrm{P}_{190}$ & $37.34 \pm 0.91^{\mathrm{bc}}$ & $14.59 \pm 0.52^{\mathrm{ab}}$ & $48.07 \pm 0.38^{\mathrm{bc}}$ \\
$\mathrm{HMC}_{50} \mathrm{P}_{190}$ & $39.34 \pm 2.40^{\mathrm{bc}}$ & $17.64 \pm 0.99^{\mathrm{d}}$ & $43.03 \pm 3.40^{\mathrm{abc}}$ \\
\hline
\end{tabular}

${ }^{\mathrm{a}-\mathrm{e}}$ Results within a column with the same superscript letters were not significantly different $(P>0.05)$.

${ }^{1} \mathrm{RMP}=$ milk powder of raw milk $(\mathrm{RM}) ; \mathrm{HMP}=$ milk powder of heated milk $(\mathrm{HM}) ; \mathrm{RMCP}=$ milk powder of concentrated RM; HMCP = milk powder of concentrated HM. The subscript numbers indicate that concentration was performed at 40 or $50^{\circ} \mathrm{C}$ and drying was performed at 160 or $190^{\circ} \mathrm{C}$.

with $2 \%$ lactose, a negligible amount of protein, and $98 \%$ fat.

During the drying process, the water in the surface layer of droplet evaporates. Therefore, the moisture content in the interior of the particles is higher than that in the surface layer, which would promote hydrophobic movement of fat to the surface of the particles. The lower the temperature is used, the longer the time of evaporation. The fat has a longer time to migrate to the surface of particles at a lower temperature. Meanwhile, the increased feed concentration of milk will increase the viscosity of droplets, reduce the drying rate, and thus increase the fat content of the particle surfaces (Kim et al., 2009b).

In this research, the surface composition of the powder particles was different due to heating $(P<0.001)$, concentration $(P<0.01)$, and drying processes $(P<$ $0.05)$ according to univariate ANOVA. These results suggest that these processes had important effects on redistribution of protein, fat, and lactose during spraydrying.

\section{Changes in Oxidized Flavor During Manufacturing and Storage}

Oxidized volatiles detected in RM, HM, concentrated milk, and corresponding milk powders mainly included straight chain aldehydes, methyl ketones, ketenes, and olefinic aldehydes. These compounds have been previously documented in milk powder and were associated with different oxidized flavors (Hall and Andersson, 1985; Hall et al., 1985; Whetstine and Drake, 2007; Lloyd et al., 2009a). Hexanal and 2-heptanone were selected as the typical oxidized volatiles to discuss the changes in oxidized flavor among the processes of heat- ing, concentration, and drying as well as the storage of milk powder.

As shown in Figure 3, oxidized volatiles levels of liquid milk (RM and HM) were found to be lower than their levels in concentrated milk and milk powder. According to the study of Vazquez-Landaverde et al. (2005), hexanal and 2-heptanone could be considered as the flavor-impact compounds in RM. In our research, their concentrations in RM were only 3.03 and $5.44 \mu \mathrm{g} / \mathrm{kg}$, respectively. The values were close to their thresholds $(\sim 5 \mu \mathrm{g} / \mathrm{kg})$. These compounds in HM were not significantly different from those in RM. However, fresh milk powder $(0 \mathrm{mo})$ in the heated groups (HMP and HMCP) had higher levels of oxidized volatiles than the corresponding unheated groups (RMP and RMCP). This indicated that the preheating treatment could promote the further formation of oxidized flavor during the production of milk powder.

Moreover, the oxidized volatiles in concentrated milk were higher than in RM and HM, which indicated that lipid oxidation occurred under the concentration conditions (i.e., low temperature and reduced pressure). Also, the concentrated milk had higher levels of oxidized volatiles than their newly produced milk powder. This result might be due to the loss of flavor in drying and the difference in flavor release of the reconstituted milk powder matrix. As for the storage of milk powder, high levels of oxidized volatiles were generated within 3 mo and increased with increased storage time $(P$ $<0.05)$. So, odor activity values of the stored milk powder were far more than 1 in all the samples (data not shown). These results validated that these compounds could be important contributors to the flavor of milk powder. Furthermore, the stored milk powder when concentrated at $40^{\circ} \mathrm{C}$ had higher levels of oxidized 
- Liquid milk Concentrated milk

$\Delta$ Milk powder - 0 mo

Milk powder - 3 mo $\nabla$ Milk powder - 6 mo
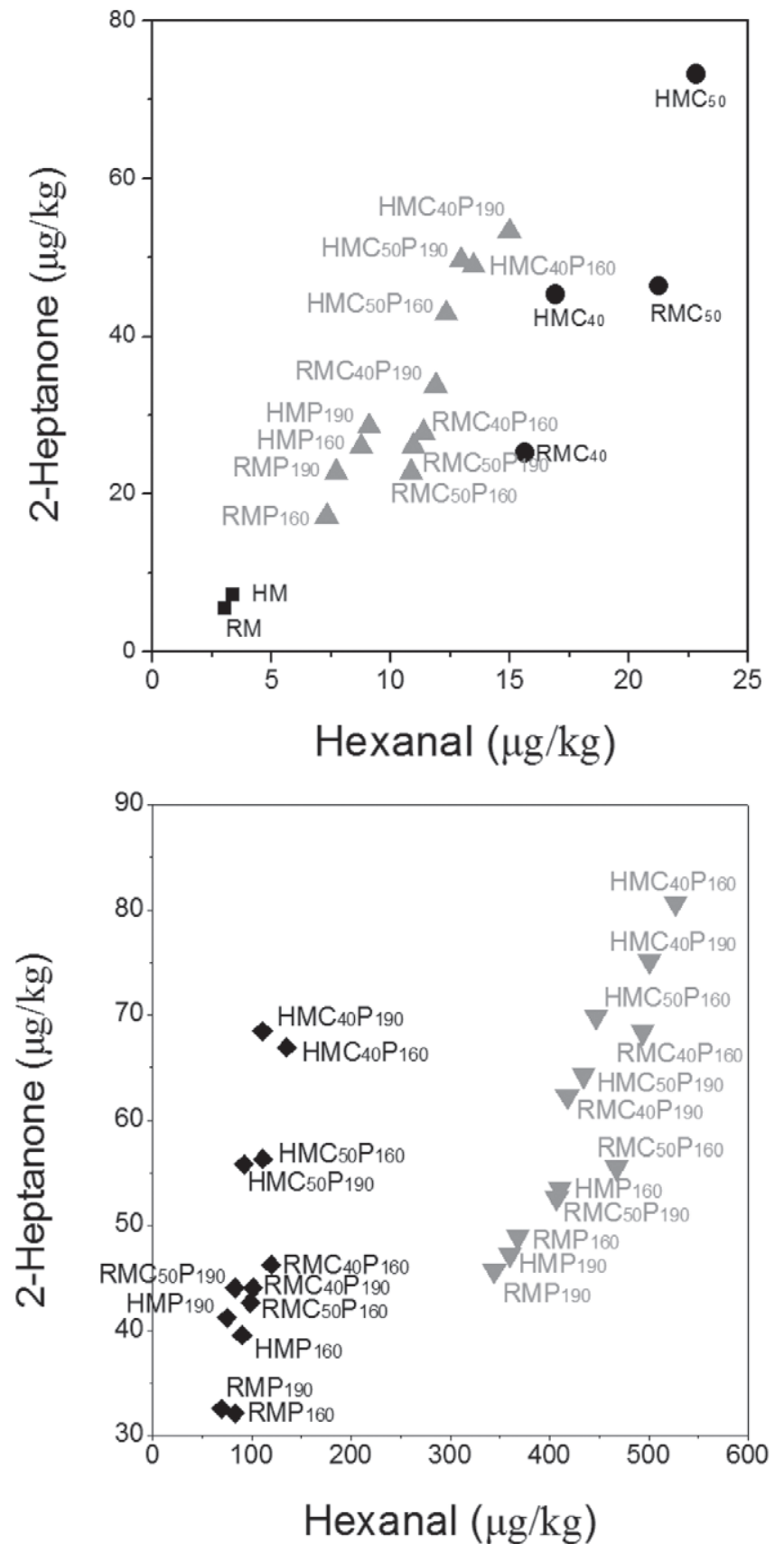

Figure 3. Changes in oxidized volatiles of milk powder during the production of milk powder and storage of 3 and 6 mo. $\mathrm{RM}=$ raw milk; $\mathrm{HM}=$ heated milk; $\mathrm{RMC}$ and $\mathrm{HMC}=$ the concentrated milk of RM and HM, respectively; RMP, HMP, RMCP, and HMCP = the milk powder of RM, HM, RMC, and HMC, respectively. The subscript numbers indicate that concentration was performed at 40 or $50^{\circ} \mathrm{C}$ and drying was performed at 160 or $190^{\circ} \mathrm{C}$. volatiles than when concentrated at $50^{\circ} \mathrm{C}$. Meanwhile, higher oxidized volatiles in stored milk powder were found when dried at $160^{\circ} \mathrm{C}$ than at $190^{\circ} \mathrm{C}$. The findings agreed with the results of univariate ANOVA: the preheating, concentration, and drying processes could influence oxidized volatiles $(P<0.05)$.

To analyze the effect of milk powder particles on the oxidized flavor, a Pearson correlation was performed. The results indicated that the volatiles in milk powder had a close correlation with the morphological attributes of particles (i.e., particle sizes in the research; $r$ $>0.565 ; P<0.05$ ). However, no relationship was found between the surface composition of particles and the oxidized flavor of powders $(P>0.05)$.

\section{Formation of Free Radical During Storage}

The ESR technique is a useful method to predict the oxidative stability of dairy products (Kristensen et al., 2002). In the study, radicals were detected in all the milk powder samples after 3 and 6 mo of storage. A typical ESR spectrum is shown in Figure 4. The mean $\mathrm{g}$ value (a characteristic constant whose value serves to identify any given free radical) of milk powder stored for $3 \mathrm{mo}$ was 2.0054, and the peak width was $7.67 \pm$ 0.35 Gauss $\left[(7.67 \pm 0.35) \times 10^{-4}\right.$ Tesla]. Although the mean $\mathrm{g}$ value decreased to 2.0050 and peak width increased to $9.78 \pm 0.22$ Gauss $\left[(9.78 \pm 0.22) \times 10^{-4}\right.$ Tesla] after 6 mo of storage, these differences could not be proven to be from 2 different species of radicals. The existence of this radical suggested the oxidation might be accelerated after storage of milk powder. This finding could be confirmed by the tremendous increase in oxidized volatiles in milk powder after storage.

The specific population (the ratio of peak area and weight of sample) was used for quantitative determination of free radicals in the milk powder. Mean levels $( \pm \mathrm{SD})$ of specific population in milk powder were 2.99 $( \pm 0.59) \times 10^{7}$ after 3 mo of storage and increased to $1.23( \pm 0.19) \times 10^{8}$ after 6 mo of storage $(P<0.05)$. It was indicated that the intensity of free radicals increased with increasing storage time of milk powder. The formation of radicals is closely related to lipid oxidation, which involves peroxidation of unsaturated FA and formation of radicals by cleavage of hydroperoxides. The volatile secondary oxidation products, considered normally to be responsible for the oxidized flavor of milk powder, are created subsequently (Kristensen et al., 2002; Thomsen et al., 2005).

\section{Effect of Antioxidant Addition on the Oxidized Flavor}

Figure 5 shows the changes in oxidized flavor after addition of antioxidants in light-exposed and light-pro- 


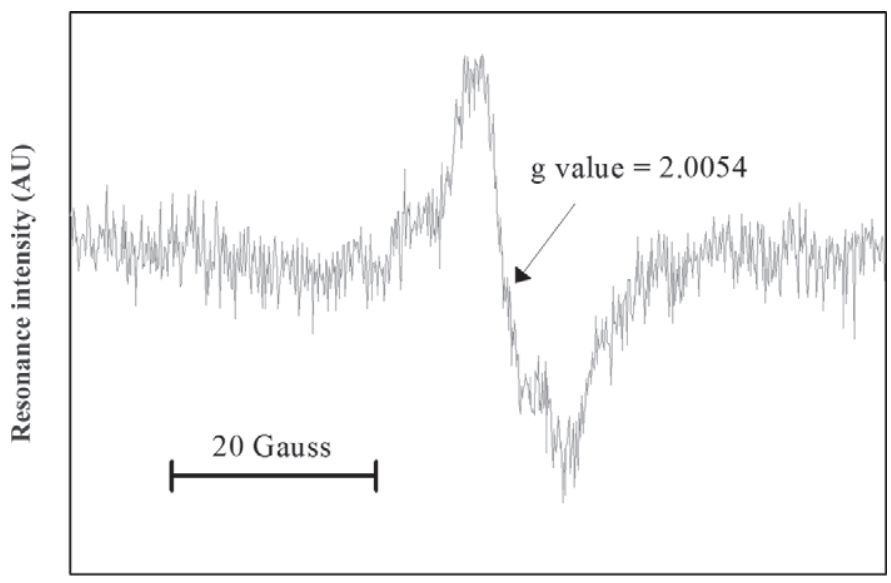

Magnetic flux density (Gauss)

Figure 4. Typical electron spin resonance (ESR) spectrum of milk powder after storage. 10,000 Gauss $=1$ Tesla. The $\mathrm{g}$ value represents a characteristic constant whose value serves to identify any given free radical.

tected milk powder. Compared with the light-protected milk powder, levels of oxidized volatiles were substantially higher in the light-exposed milk powder.

In light-protected milk powder (Figure 5B), ASC decreased the levels of hexanal and 2-heptanone compared with the treatment without any addition (control); TOC as well as the combination of ASC and TOC had no effect on the volatiles. In light-exposed milk powder (Figure 5A), addition of ASC only decreased the level of hexanal compared with the control; TOC and ASC + TOC had no effect on the volatiles. Although no significant difference was observed, the addition of TOC seemed to increase the intensities of hexanal and 2-heptanone. This agreed with some previous studies that considered that TOC could be an indication of a pro-oxidant effect of the antioxidant (Frankel, 1998; van Aardt, 2005).

The typical differential ESR spectrums of radicals in milk powder with addition of antioxidants are shown in Figure 6. Addition of ASC (Figure 6B) and ASC + TOC (Figure 6C) in milk powder displayed a clear difference in the spectrum shape and in the intensity of radicals compared with the TOC milk powder (Figure $6 \mathrm{~A}$ ) and control (Figure 6D), regardless of the light exposure. In ASC and ASC + TOC milk powder, the differential ESR spectrums seemed to demonstrate an overlap of 2 species of radicals. With the integral spectrum, the overlapping was observed clearly as shown in the insert plot of Figure $6 \mathrm{~B}$.

The generation of 2 types of radicals in ASC milk powder indicated that addition of ASC could induce the formation of a new radical treated as the ASC-induced radical, because ASC could be broadly classified as

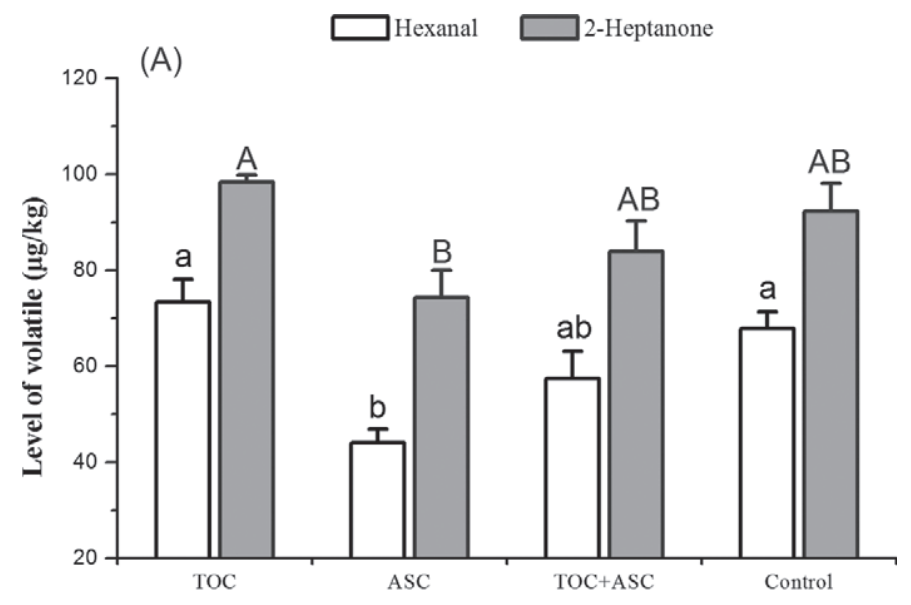

(B)



Figure 5. Differences in oxidized volatiles of milk powder with addition of different antioxidants: (A) light-exposed storage and (B) light-protected storage. The results with the same letters (a and $\mathrm{b}$, and $\mathrm{A}$ and $\mathrm{B})$ for each volatile are not significantly different $(P>0.05)$. TOC $=\alpha$-tocopherol; ASC $=$ ascorbic acid.

an oxygen scavenger/singlet oxygen quencher reacting with free oxygen (Madhavi et al., 1996). Obviously, the ASC-induced radical inhibited the formation of lipid oxidation, resulting in the decrease of oxidized flavor in milk powder by $34.98 \%$ for hexanal and $19.57 \%$ for 2-heptanone under light exposure, and by $52.31 \%$ for hexanal and $31.13 \%$ for 2-heptanone under light protection.

\section{CONCLUSIONS}

In the paper, we found that the particle diameters of milk powder were affected by the concentrated intensity and drying temperature. According to the result of XPS, the surface composition of powder particles was different among milk powder samples due to heating, concentration, and drying processes. Also, these processes influenced the levels of oxidized volatiles. 



Figure 6. Electron spin resonance (ESR) spectra of radicals in milk powder with addition of different antioxidants: (A) $\alpha$-tocopherol (TOC), (B) ascorbic acid (ASC), (C) TOC + ASC, and (D) control. Scale size = 20 Gauss (10,000 Gauss = 1 Tesla).

However, not the surface compositions but the morphological characteristics of milk powder particles had a high correlation with the stability of oxidized flavor in storage. Meanwhile, a radical was detected in stored milk powder and increased with increasing storage time. Addition of ASC in milk powder induced a new type of radical and decreased the oxidized flavor.

\section{ACKNOWLEDGMENTS}

The work was financially supported by Key Projects in the National Science \& Technology Pillar Program (PR China) during the Eleventh Five-Year Plan Period (No. 2006BAD04A06) and the Twelfth Five-Year Plan Period (No. 2013BAD18B05).

\section{REFERENCES}

Almeida, K. E., A. Y. Tamime, and M. N. Oliveira. 2009. Influence of total solids contents of milk whey on the acidifying profile and viability of various lactic acid bacteria. Lebensm. Wiss. Technol. 42:672-678.

Baldwin, A. J., H. R. Cooper, and K. C. Palmer. 1991. Effect of preheat treatment and storage on the properties of whole milk powder-changes in sensory properties. Neth. Milk Dairy J. 45:97-116.

Bullman, V. 2003. Automated three-dimensional analysis of particle measurements using an optical profilometer and image analysis software. J. Microsc. 211:95-100.

Cadwallader, K. R., and T. K. Singh. 2009. Flavours and off-flavours in milk and dairy products. Pages 633-635 in Advanced Dairy Chemistry. P. L. H. McSweeney and P. F. Fox, ed. Springer Science and Business Media, LLC, New York, NY.

Frankel, E. N. 1998. Antioxidants. Pages 129-160 in Lipid Oxidation. The Oily Press Ltd., Dundee, Scotland.

Guinee, T. P., M. A. E. Auty, and M. A. Fenelon. 2000. The effect of fat content on the rheology, microstructure and heat-induced functional characteristics of Cheddar cheese. Int. Dairy J. 10:277-288. 
Hall, G., and J. Andersson. 1985. Flavor changes in whole milk powder during storage. III. Relationships between flavor properties and volatile compounds. J. Food Qual. 7:237-253.

Hall, G., J. Andersson, H. Lingnert, and B. Olofsson. 1985. Flavor changes in whole milk powder during storage. II. The kinetics of the formation of volatile fat oxidation products and other volatile compounds. J. Food Qual. 7:153-190.

Hassan, H. M., and C. J. Mumford. 1993. Mechanisms of drying of skin-forming materials. III. Droplets of natural products. Drying Technol. 11:1765-1782.

Hedegaard, R. V., D. Kristensen, J. H. Nielsen, M. B. Frost, H. Østdal, J. E. Hermansen, M. Kröger-Ohlsen, and L. H. Skibsted. 2006. Comparison of descriptive sensory analysis and chemical analysis for oxidative changes in milk. J. Dairy Sci. 89:495-504.

Kim, E. H.-J., X. D. Chen, and D. Pearce. 2002. Surface characterization of four industrial spray-dried dairy powders in relation to chemical composition, structure and wetting property. Colloids Surf. B Biointerfaces 26:197-212.

Kim, E. H.-J., X. D. Chen, and D. Pearce. 2003. On the mechanisms of surface formation and the surface compositions of industrial milk powders. Drying Technol. 21:265-278.

Kim, E. H.-J., X. D. Chen, and D. Pearce. 2005. Melting characteristics of fat present on the surface of industrial spray-dried dairy powders. Colloids Surf. B Biointerfaces 42:1-8.

Kim, E. H.-J., X. D. Chen, and D. Pearce. 2009a. Surface composition of industrial spray-dried milk powders. 1. Development of surface composition during manufacture. J. Food Eng. 94:163-168.

Kim, E. H.-J., X. D. Chen, and D. Pearce. 2009b. Surface composition of industrial spray-dried milk powders. 2. Effects of spray drying conditions on the surface composition. J. Food Eng. 94:169-181.

Kristensen, D., M. V. Kröger-Ohlsen, and L. H. Skibsted. 2002. Radical formation in dairy products: Prediction of oxidative stability based on electron spin resonance spectroscopy. Pages 114-125 in Free Radicals in Food. M. J. Morello, F. Shahidi, and Chi-Tang Ho, ed. ACS Publishing, Washington, DC.

Lee, S. J., and J. W. Sherbon. 2002. Chemical changes in bovine milk fat globule membrane caused by heat treatment and homogenization of whole milk. J. Dairy Res. 69:555-567.

Li, Y., L. Zhang, and W. Wang. 2012. Heat-induced changes in volatiles of milk and effects of thermal processing on microbial metabolism of yogurt. J. Food Biochem. http://dx.doi.org/10.1111/ j.1745-4514.2011.00642.x.

Lloyd, M. A., M. A. Drake, and P. D. Gerard. 2009a. Flavor variability and flavor stability of U.S.-produced whole milk powder. J. Food Sci. 74:S334-S343.
Lloyd, M. A., S. J. Hess, and M. A. Drake. 2009b. Effect of nitrogen flushing and storage temperature on flavor and shelf-life of whole milk powder. J. Dairy Sci. 92:2409-2422.

Madhavi, D. L., S. S. Deshpande, and D. K. Salunkhe. 1996. Introduction. Pages 1-4 in Food Antioxidants: Technological, Toxicological, and Health Perspectives. D. L. Madhavi, S. S. Deshpande, and D. K. Salunkhe, ed. Marcel Dekker Inc., New York, NY.

Nielsen, B. R., H. Stapelfeldt, and L. H. Skibsted. 1997. Early prediction of the shelf-life of medium-heat whole milk powders using stepwise multiple regression and principal component analysis. Int. Dairy J. 7:341-348.

Stapelfeldt, H., B. R. Nielsen, and L. H. Skibsted. 1997. Effect of heat treatment, water activity and storage temperature on the oxidative stability of whole milk powder. Int. Dairy J. 7:331-339.

Thomsen, M. K., L. Lauridsen, L. H. Skibsted, and J. Risbo. 2005. Two types of radicals in whole milk powder. Effect of lactose crystallization, lipid oxidation, and browning reactions. J. Agric. Food Chem. 53:1805-1811.

Timmons, J. S., W. P. Weiss, D. L. Palmquist, and W. J. Harper. 2001. Relationships among dietary roasted soybeans, milk components, and spontaneous oxidized flavor of milk. J. Dairy Sci. 84:2440-2449.

van Aardt, M., S. E. Duncan, J. E. Marcy, T. E. Long, S. F. O'Keefe, and S. R. Nielsen-Sims. 2005. Effect of antioxidant ( $\alpha$-tocopherol and ascorbic acid) fortification on light-induced flavor of milk. J. Dairy Sci. 88:872-880

Vazquez-Landaverde, P. A., G. Velazquez, J. A. Torres, and M. C. Qian. 2005. Quantitative determination of thermally derived offflavor compounds in milk using solid-phase microextraction and gas chromatography. J. Dairy Sci. 88:3764-3772.

Vignolles, M.-L., C. Lopez, C. Le Floch-Fouéré, J.-J. Ehrhardt, S. Méjean, R. Jeantet, and P. Schuck. 2010. Fat supramolecular structure in fat-filled dairy powders: A tool to adjust spray-drying temperatures. Dairy Sci. Technol. 90:287-300.

Vignolles, M.-L., R. Jeantet, C. Lopez, and P. Schuck. 2007. Free fat, surface fat and dairy powders: Interactions between process and product. A review. Lait 87:187-236.

Whetstine, M. E. C., and M. A. Drake. 2007. The flavor and flavor stability of skim and whole milk powders. Pages 217-251 in Flavor of Dairy Products. K. R. Cadwallader, M. A. Drake, and R. McGorrin, ed. ACS Publishing, Washington, DC. 